\title{
A Heterogeneous-Based and Microwave-Assisted Protocol for the Synthesis of 2,2'-Bipyridines
}

\author{
Lucas R. Moore and David A. Vicic ${ }^{a}$ \\ David A. Vicic: vicic@hawaii.edu \\ aDepartment of Chemistry, University of Hawaii, 2545 McCarthy Mall, Honolulu. HI 96822, USA. \\ Fax: (+1) 808-956-5908
}

\section{Abstract}

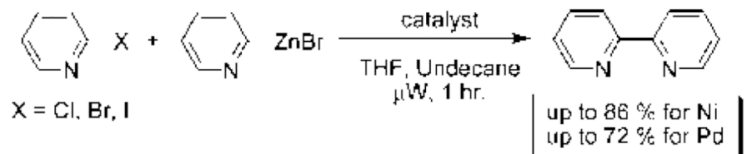

\begin{abstract}
A new method to prepare 2,2'-bipyridines in short reaction times using microwave assistance and heterogeneous catalysts has been developed. Using a Negishi-like protocol, it was found that $\mathrm{Ni} /$ $\mathrm{Al}_{2} \mathrm{O}_{3}-\mathrm{SiO}_{2}$ afforded 2,2'-bipyridine products in up to $86 \%$ yields in $1 \mathrm{~h}$. Palladium supported on alumina also provided comparable yields of 2,2'-bipyridines to that seen for homogeneous PEPPSI $^{\mathrm{TM}}$ and tetrakis(triphenylphosphine) palladium complexes.
\end{abstract}

\section{Keywords}

C-C Coupling; nickel; palladium; microwave; heterogeneous catalysis

\section{Introduction}

Carbon-carbon and carbon-heteroatom coupling reactions have been shown to be incredibly useful synthetic tools for a variety of synthetic applications, such as the synthesis of natural products and pharmaceuticals.1, 2 The success of a coupling reaction is limited to the activity of the catalyst for a particular transformation, which in most cases is directly correlated to the ligands coordinated to the metal. The synthesis of new heterocycles, such as those containing pyridine rings for example, is especially important for the pharmaceutical industry. While $\mathrm{C}_{\text {pyridyl }}-\mathrm{C}_{\text {aryl }}$ cross-couplings are well-known with palladium, the certain aspects of bipyridyl syntheses have always been problematic. Scheme 1 describes the general cross-coupling methods used to prepare different isomers of the bipyridyl family. Methods to prepare bipyridyls 2 and $\mathbf{3}$ are well-known6 $6^{-}$11, but strikingly absent are any reliable methods to prepare unsymmetrically substituted 2,2'-bipyridyls (4) that are broad in scope. This is presumably due to the fact that bipyridyls are effective transition-metal binding agents, so any homogeneous metal-catalyzed reaction to produce them will suffer from marked product inhibition effects. Achieving a high-yielding method to construct the bipyridyl framework would not only be important for drug discovery endeavors, but will also significantly affect the field of inorganic chemistry, where polypyridyl ligands are used quite frequently. $3^{-6}$

Correspondence to: David A. Vicic, vicic@hawaii.edu.

Supporting information for this article is available on the WWW under http://www.chemasianj.org or from the author. 
Current protocols to prepare 2,2'-bipyridines involve lithiation-addition, 7, 8 radical anion coupling,9 Stille,10, 11 Suzuki,12 Kumada,13, 14 and Negishi15-19 reactions. All of these methods have limitations, 15 and most employ homocoupling20-27 methodologies. Some cross-couplings have been reported, but all involve extremely extended reaction times.1519, 28 Heller reports yields of 2,2'- bipyridines ranging from 56-87\% when Stille coupling was used, but those results involve refluxing in toluene for 48 hours. 28 Hanan reports yields ranging from 68-98\% when a Negishi protocol was used, with reaction times ranging from 18 to 40 hours with temperatures ranging from room temperature to $60^{\circ} \mathrm{C} .15$ Here we report a convenient additional protocol to prepare 2,2'-bipyridines using heterogeneous palladium and nickel catalysts with the assistance of microwave irradiation. The major advantages of these conditions are the ease product separation and the extremely fast reaction times relative to previously reported procedures.

\section{Results and Discussion}

Attempts were made to synthesize 2,2'-bipyridine under thermal conditions with the use of heterogeneous palladium and nickel catalysts suspended in THF. When applying either nickel or palladium supported on carbon, silica, and alumina no activity was observed for the coupling of iodo-, bromo-, or chloropyridines with either pyridylzinc bromide or pyridinium- $N$-oxide, 29 even under refluxing temperatures $\left(90{ }^{\circ} \mathrm{C}\right)$ for 23 hours with $5 \mathrm{~mol}$ $\%$ catalyst loadings (Table 1, entries 7-12, 19-24, and 31-36). However, increasing the amount of nickel to $50 \mathrm{~mol} \%$ supported on silica or alumina-silica mixture (Table 1, entries $1-3,13-15$, and 25-27) showed some conversion to the desired 2,2'-bipyridines, indicating that optimization of these initial nickel reactions may provide more respectable yields (see below). Increasing the amount of palladium to $50 \mathrm{~mol} \%$ showed no increase in product formation for the thermal reactions (Table 1, entries 4-6, 16-18, and 28-30). Interestingly, crystallization of (bpy) $\mathrm{ZnBr}_{2}$ from THF (as determined by X-ray crystallography) is observed at the conclusion of every successful reaction, which can provide a crude way of rapidly determining which set of conditions are promising. Because of the ability of bipyridines to bind avidly to transition metals, all crude product mixtures for this study were treated with ammonium hydroxide to release free bipyridines before chromatography.

In light of the fact that some conversion to 2,2'-bipyridine products was observed with $50 \%$ nickel loadings in the thermal reactions, we explored the possibility of using microwaves to further increase yields. The results are summarized in Table 2. The yields of 2,2'-bipyridines rose to the $80 \%$ range, with the most practical conditions employing $\mathrm{Ni} / \mathrm{Al}_{2} \mathrm{O}_{3}-\mathrm{SiO}_{2}$ as the catalyst with no phosphine required (Table 2, entry 1c). One hour was chosen as a time limit for the irradiations because we saw significantly less conversions at $20 \mathrm{~min}$. $\mathrm{PPh}_{3}$ had little effect on the yields of this reaction (Table 2, entry 1a), however the addition of a more electron rich phosphine $\mathrm{P}(t-\mathrm{Bu})_{3}$ actually lowered observed yields (Table 2 , entry $\left.1 \mathrm{~b}\right)$. The pyridylzinc nucleophile and the nickel catalyst are needed for the reaction to proceed, as control reactions performed in the absence of these reagents resulted in no product formation (Table 2, entries 2 and 3). A huge steric effect is seen with these reactions; however, as placement of a methyl group in either the 6- or 3-position of the pyridylbromide shut down catalysis entirely and also produced no homocoupled product (Table 2, entries 4 and 5).

We also wondered whether the microwave conditions could help the palladium-catalyzed heterogeneous reactions, and the results of this study are summarized in Table 3. Yields comparable to those found with the nickel-supported thermal reactions were obtained at a wattage of 250 (Table 3, entries 4 and 6), and also required a catalyst loading of only $5 \mathrm{~mol}$ $\%$. These yields can be increased to 66-72\% with an increase in wattage to 300 (Table 3 , entries 1a and 3). This wattage was maintained throughout the course of the reaction. The $\mathrm{Pd} / \mathrm{Al}_{2} \mathrm{O}_{3}$ catalyzed coupling of 2-bromopyridine under microwave conditions yielded 
comparable results to those found with homogeneous $\mathrm{Pd}\left(\mathrm{PPh}_{3}\right)_{4}$ (Table 3, entry 1g) and greater than that found for PEPPSI ${ }^{\mathrm{TM}}$ (Table 3 , entry $1 \mathrm{~h}$ ) catalyzed coupling under the same conditions. Applications of more polar solvents proved to be unsuccessful with yields dropping to $28 \%$ for dioxane (entry $1 \mathrm{~b}$ ) and $4 \%$ for DMF (entry 1c). Even at $300 \mathrm{~W}$, Stille and Kumada couplings of 2- bromopyridine with 2-pyridyl-tributyltin or 2pyridylmagnesium bromide were unsuccessful (entries 7 and 8 ) when a palladium catalyst was applied. Iron is known to be effective catalyst for Kumada-like cross-couplings,30, 31 but a heterogeneous iron supported catalyst only afforded a $2 \%$ yield (entry 9 ).

Finally, we tested the ability of supported palladium to prepare unsymmetrically substituted 2,2'-bipyridines (Table 4). Some homocoupling of both the electrophile and nucleophile was observed, but the major product in all cases was that resulting from cross-coupling. A 33\% yield of the desired product was obtained with the methyl group located in the six position (Table 4, entry 1).

Yields approaching those of a nonsubstituted electrophile were obtained when the methyl group was in the 3 position, and such yields were also obtained when the methyl group was placed in the 5 position (Table 4, entries 2 and 3). Though no homocoupling was observed during the reaction of 2-bromo-4-methyl-pyridine, a 36\% yield was obtained for the desired product (Table 4, entry 4).

\section{Conclusion}

A convenient new protocol employing heterogeneous catalysts and microwave irradiation to prepare 2,2'-bipyridines has been discovered. The major benefits of this reaction is the ease of product purification and especially short reaction times. Heterogeneous $\mathrm{Pd} / \mathrm{Al}_{2} \mathrm{O}_{3}$ has proven to be as effective in the Negishi couplings of 2-bromopyridines with pyridylzinc bromide to two commonly used homogeneous catalysts- $\mathrm{Pd}\left(\mathrm{PPh}_{3}\right)_{4}$ and PEPPSI ${ }^{\mathrm{TM}}$. Ni/ $\mathrm{Al}_{2} \mathrm{O}_{3}-\mathrm{SiO}_{2}$ provided the best yields of bipyridine product, but at much higher catalyst loadings.

\section{Experimental Section}

All reagents where mixed in a glovebox under an atmosphere of nitrogen prior to irradiation. THF was distilled over sodium and benzophenone followed by storing in the glovebox. Both the pyridylzinc and magnesium bromides were purchased from Rieke Metals and were used without further purification. PEPPSI ${ }^{\mathrm{TM}}$ was purchased from Sigma Aldrich, the nickel supported on carbon (graphite) was purchased from Alfa Aesar, and all other catalysts were purchased from Strem Chemicals. All the catalysts were used without further purification. Microwave reactions were carried out while maintaining a temperature of $90{ }^{\circ} \mathrm{C}$ using a CEM Discover System with an Explorer auto-sampler attachment. Undecane was applied as the internal standard.

Representative example of the microwave assisted reactions using 5 mol\% catalyst: While in the glovebox the desired 2-halopyridine $(0.67 \mathrm{mmol})$, metal catalyst $(0.0335 \mathrm{mmol})$, pyridyl zincbromide $0.5 \mathrm{M}$ in THF (1.36 mL, $0.68 \mathrm{mmol})$, distilled THF $(4 \mathrm{~mL})$, and undecane $(0.05$ $\mathrm{mL}, 0.24 \mathrm{mmol}$ ) were added to a $10 \mathrm{~mL}$ CEM crimp-top vial equipped with a stirbar. The reaction vial was placed in a CEM Discover Microwave using the following specifications: Power: $300 \mathrm{~W}$, Time: 60 minutes. The crude reaction mixtures were allowed to stir with ammonium hydroxide $30 \mathrm{wt} \%(2 \mathrm{~mL})$ for 30 minutes to remove any bipyridines that may be coordinated to the $\mathrm{Zn}$. A crude sample was then removed and filtered through a silica plug followed by rinsing with ether. The yields of the reactions were calculated by GC on a Shimadzu GC-17A (applying undecane as the internal standard). 
Representative example of the thermal reactions using 5 mol\% catalyst: All the reagent concentrations were maintained the same as in the previously mention microwave procedure, however, $25 \mathrm{~mL}$ reaction vials were used along with a Radleys 12 Reaction Station Carousel that allowed refluxing $\left(90^{\circ} \mathrm{C}\right)$ under nitrogen. The reactions were allowed to reflux for 24 hours at which time they were cooled to room temperature. The work-up procedure described above was then followed

\section{Acknowledgments}

We thank David Bateman and Matthias McIntosh from the University of Arkansas for their assistance and advice with the microwave reactor. Support of this work provided by NIH COBRE (RR-015569-06) and the Office of Basic Energy Sciences of the U. S. Department of Energy (DE-FG02-07ER15885).

\section{References}

1. Herrmann WA, Bohm VPW, Reisinger C-P. J. Chem. Ed. 2000; 77:92-95.

2. Li C-J. Chem. Rev. 2005; 105:3095-3165. [PubMed: 16092827]

3. Drentand E, Budzelaar PH. Chem. Rev. 1996; 96:663-681. [PubMed: 11848769]

4. Gavryushin A, Kofink C, Manolikakes G, Knochel P. Tetrahedron. 2006; 62:7521-7533.

5. Anderson TJ, Jones GD, Vicic DA. J. Amer. Chem. Soc. 2004; 126:8100-8101. [PubMed: 15225035]

6. Kaes C, Katz A, Hosseini MW. Chem. Rev. 2000; 100:3553-3590. [PubMed: 11749322]

7. Ward MD, McCleverty JA, Jeffery JC. Coord. Chem. Rev. 2001; 222:251-272.

8. Ward MD. J. Chem. Soc., Dalton Trans: Inorg. Chem. 1994:3095-3098.

9. Newkome GR, Hager DC. J. Org. Chem. 1982; 47:599-601.

10. Hanan GS, Lehn J-M, Kyritsakas N, Fischer J. J. Chem. Soc., Chem. Commun. 1995:765-766.

11. Hanan GS, Schubert US, Volkmer D, Riviere E, Lehn J-M, Kyritsakas N, Fischer J. Can. J. Chemistry. 1997; 75:169-182.

12. Deshayes K, Broene RD, Chao I, Knobler CB, Diederich F. J. Org. Chem. 1991; 56:6787-6795.

13. Berillon L, Lepretre A, Turck A, Ple N, Queguiner G, Cahiez G, Knochel P. Synlett. 1998:1359_ 1360.

14. Rottlander M, Boymond L, Berillon L, Lepretre A, Varchi G, Avolio S, Laaziri H, Queguiner G, Ricci A, Cahiez G, Knochel P. Chem-Eur. J. 2000; 6:767-770.

15. Fang Y-Q, Hanan GS. Synlett. 2003:852-854.

16. Trecourt F, Gervais B, Mallet M, Queguiner G. J. Org. Chem. 1996; 61:1673-1676. [PubMed: 11667035]

17. Savage SA, Smith AP, Fraser CL. J. Org. Chem. 1998:10048-10051.

18. Lützen A, Hapke M. Eur. J. Org. Chem. 2002:2292-2297.

19. Lützen A, Hapke M, Staats H, Bunzen J. Eur. J. Org. Chem. 2003:3948-3957.

20. de Franca KWR, de Lira Oliveira J, Florêncio T, da Silva AP, Navarro M, Léonel E, Nédélec J-Y. J. Org. Chem. 2005; 70:10778-10781. [PubMed: 16356000]

21. de França KWR, Navarro M, Léonel E, Durandetti M, Nédélec J-Y. J. Org. Chem. 2002; 67:18381842. [PubMed: 11895400]

22. Kuroboshi M, Waki Y, Tanaka H. J. Org. Chem. 2003; 68:3938-3942. [PubMed: 12737575]

23. Hennings DD, Iwama T, Rawal VH. Org. Lett. 1999; 1:1205-1208.

24. Lin, G-q; Hong, R. J. Org. Chem. 2001; 66:2877-2880. [PubMed: 11304218]

25. Kang S-K, Baik T-G, Jiao XH, Lee Y-T. Tet. Lett. 1999; 40:2383-2384.

26. Shirakawa E, Nakao Y, Murota Y, Hiyama T. J. Organomet. Chem. 2003; 670:132-136.

27. Hassan J, Penalva V, Lavenot L, Gozzi C, Lemaire M. Tetrahedron. 1998; 54:13793-13804.

28. Schubert US, Eschbaumer C, Heller M. Org. Lett. 2000; 2:3373-3376. [PubMed: 11029214]

29. Campeau L-C, Rousseaux S, Fagnou K. J. Amer. Chem. Soc. 2005; 127:18020-18021. [PubMed: 16366550] 
30. Dongol KG, Koh H, Sau M, Chai CLL. Adv. Synth. Catal. 2007; 349:1015-1018.

31. Hoelzer B, Hoffmann RW. Chem. Commun. 2003:732-733. 


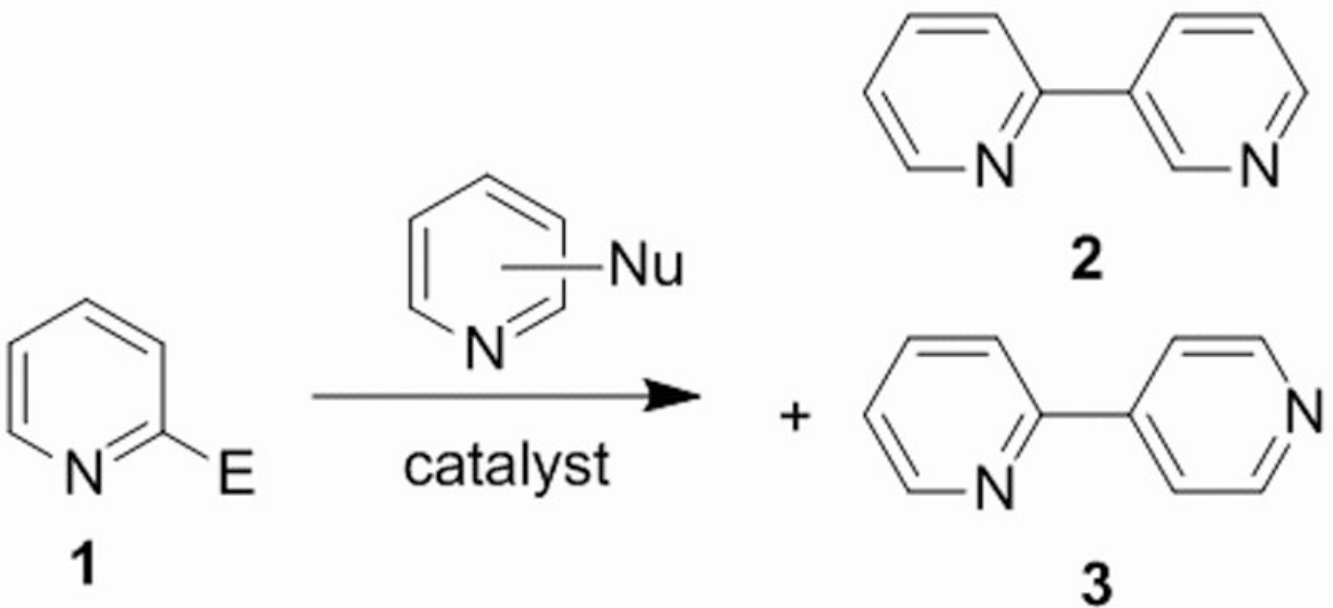

$$
\begin{gathered}
\mathbf{E}=\mathrm{Cl}, \mathrm{Br}, \mathrm{I} \\
\mathrm{Nu}=\mathrm{B}(\mathrm{OR})_{2}, \\
\mathrm{ZnBr}, \mathrm{SnR}_{3}, \mathrm{MgX}
\end{gathered}
$$

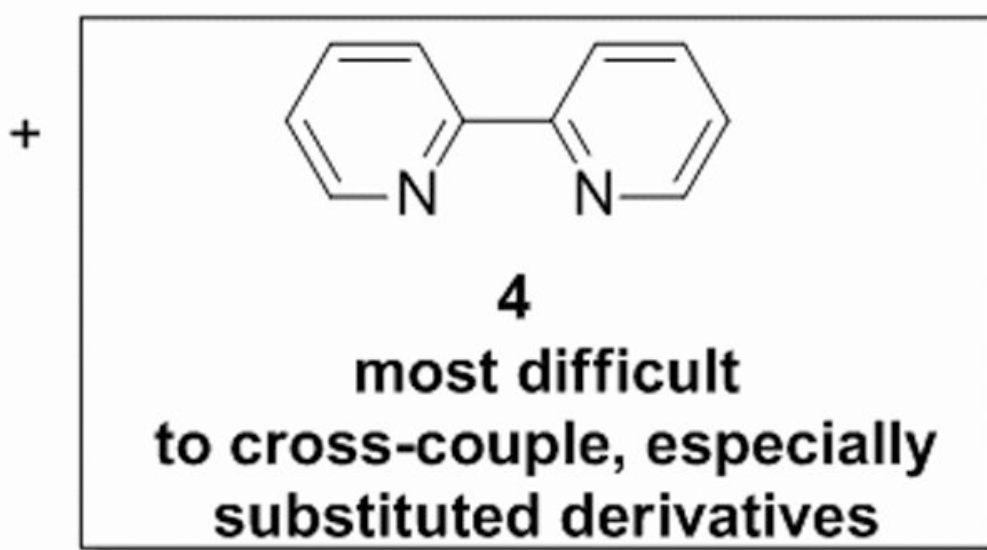

Scheme 1.

Scope of cross-couplings of 2-halo-pyridines withy pyridyl nucleophiles is highly dependent on substitution patterns. 


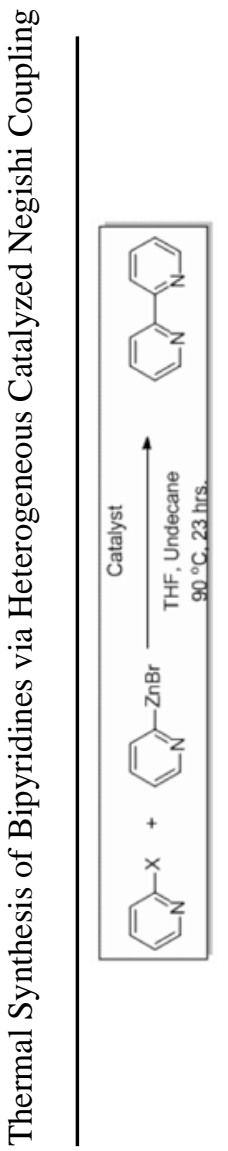

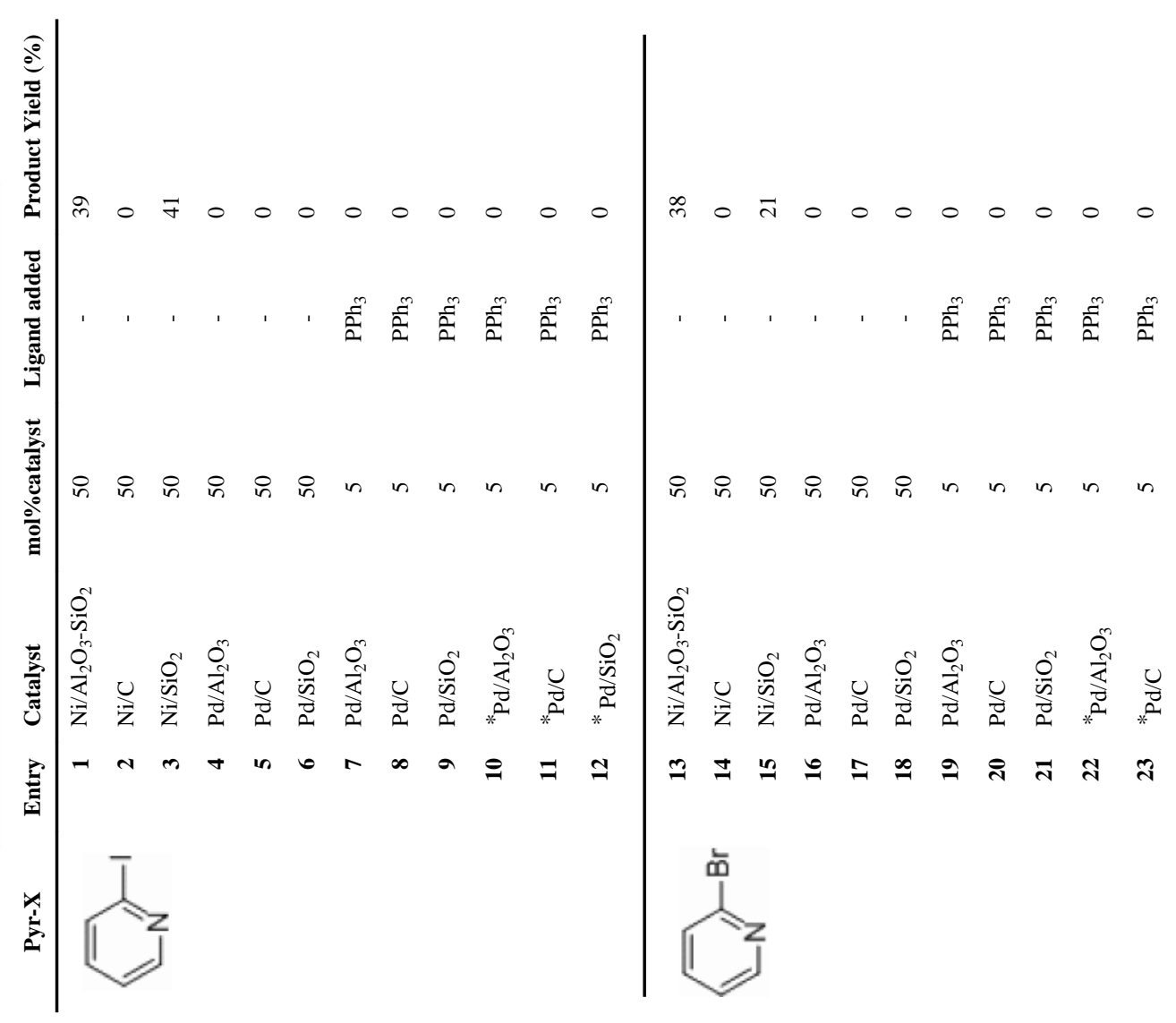

Chem Asian J. Author manuscript; available in PMC 2010 May 25. 


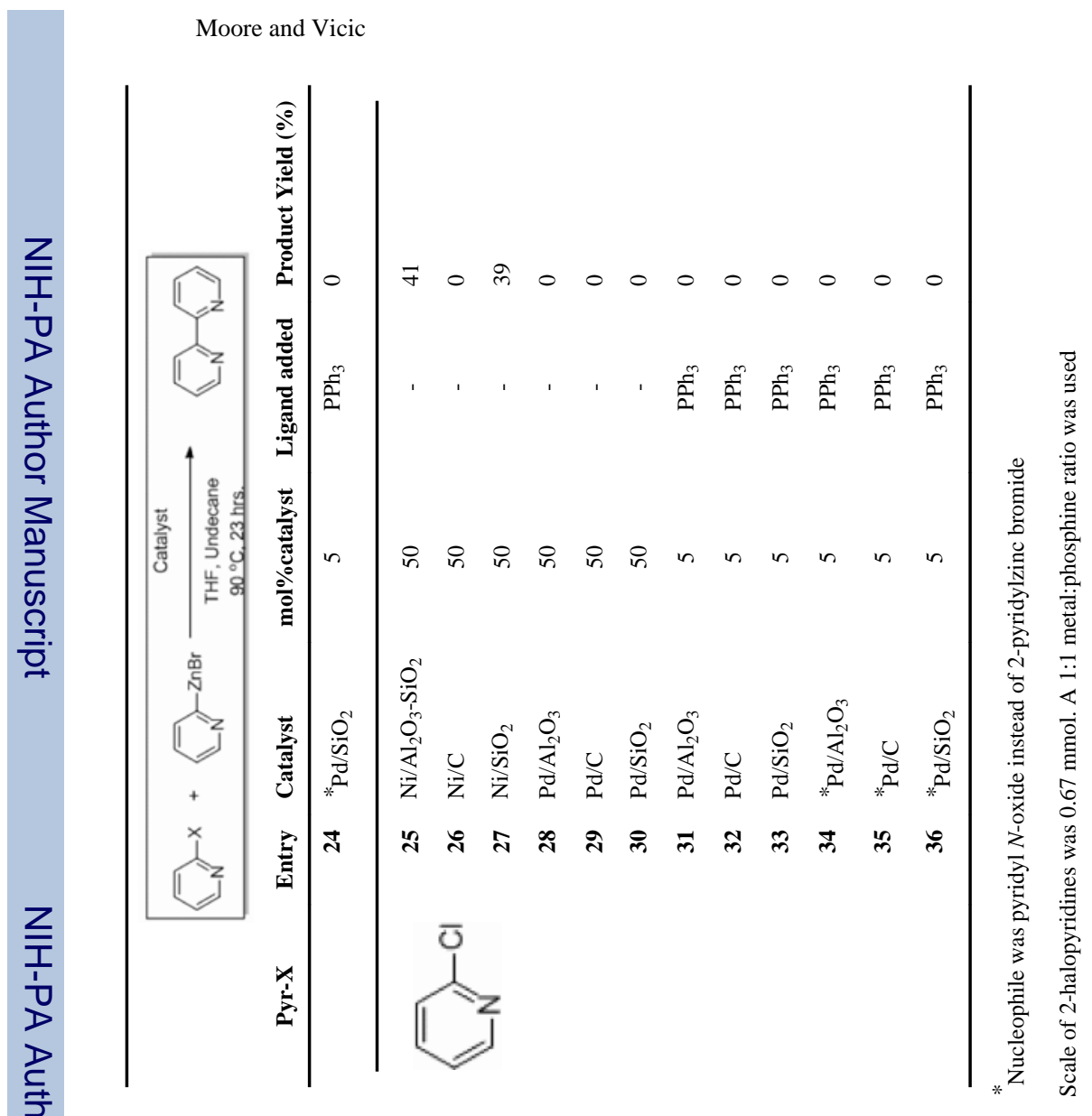

Page 8 


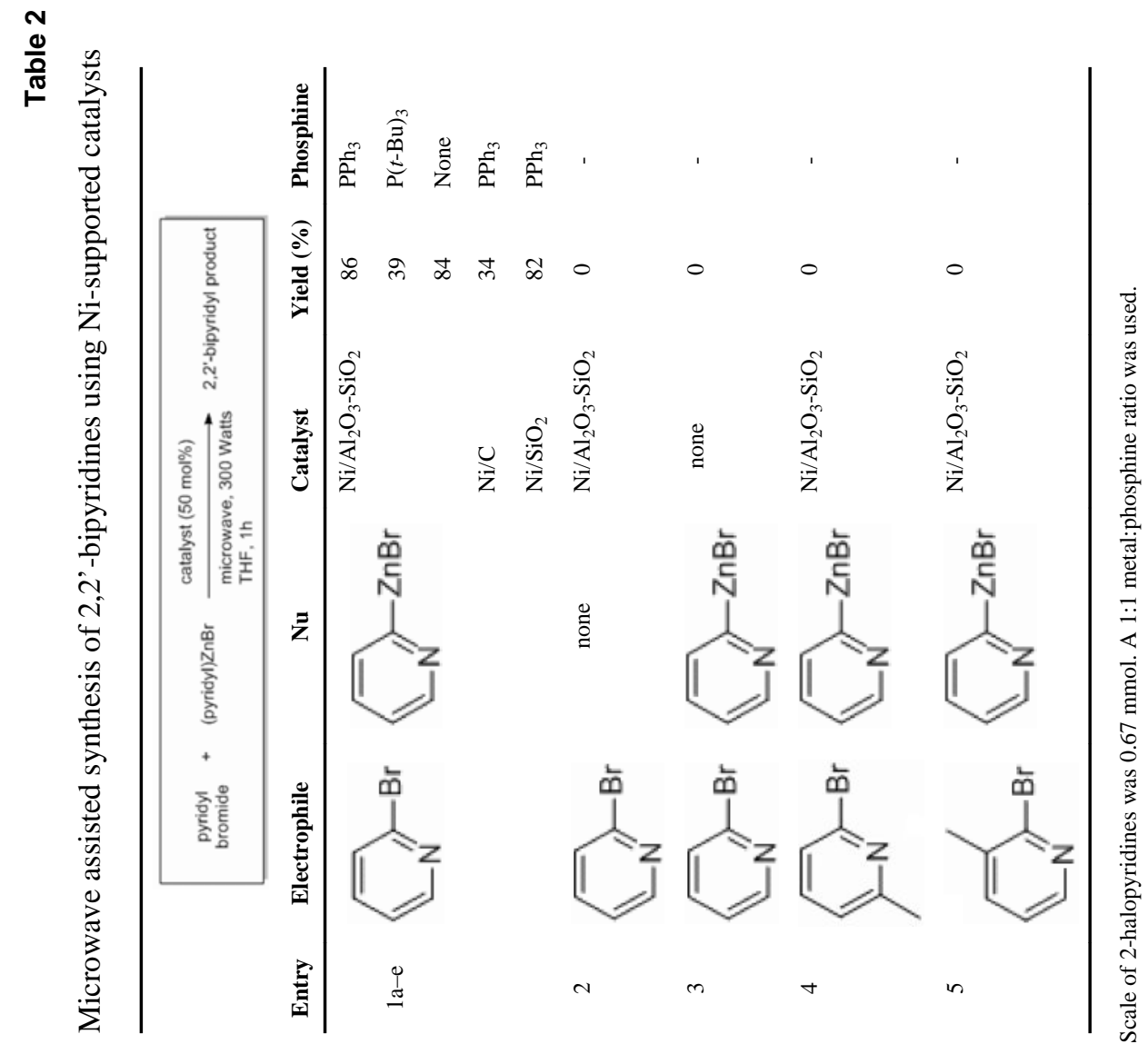

Chem Asian J. Author manuscript; available in PMC 2010 May 25. 
$\frac{\infty}{\frac{0}{0}}$

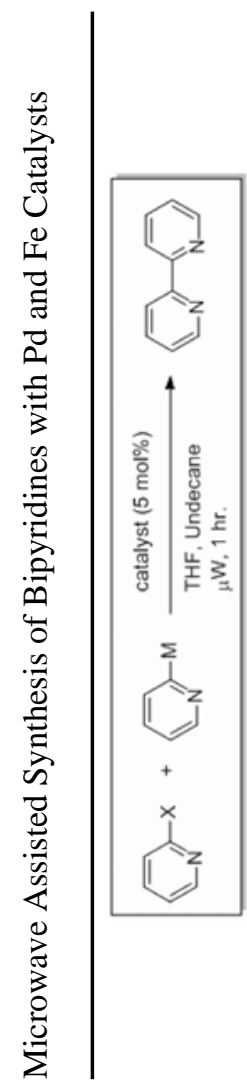

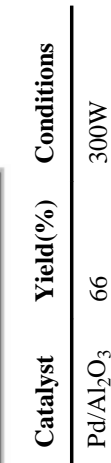

:<smiles>[N]c1ccccc1</smiles><smiles>Oc1ccccc1</smiles>
至

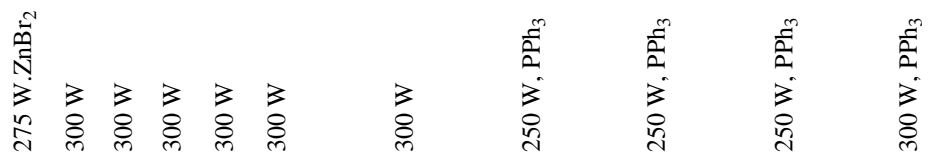

के

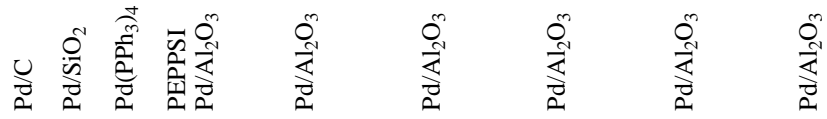

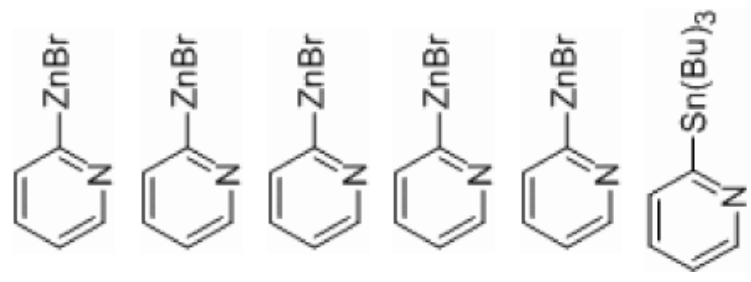<smiles>Cc1ccccc1Oc1ccccc1[Te]c1ccccc1</smiles>

Chem Asian J. Author manuscript; available in PMC 2010 May 25. 


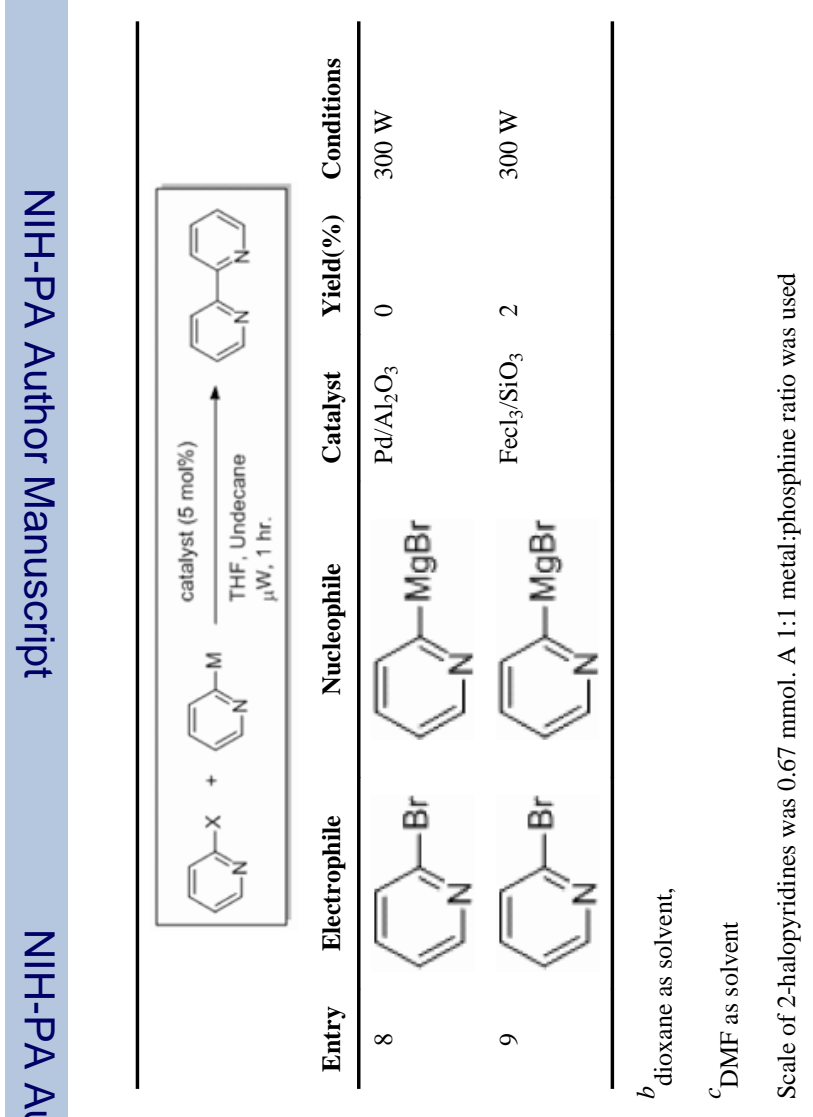


Table 4

Microwave Assisted Synthesis of Unsymmetrical Bipyridines

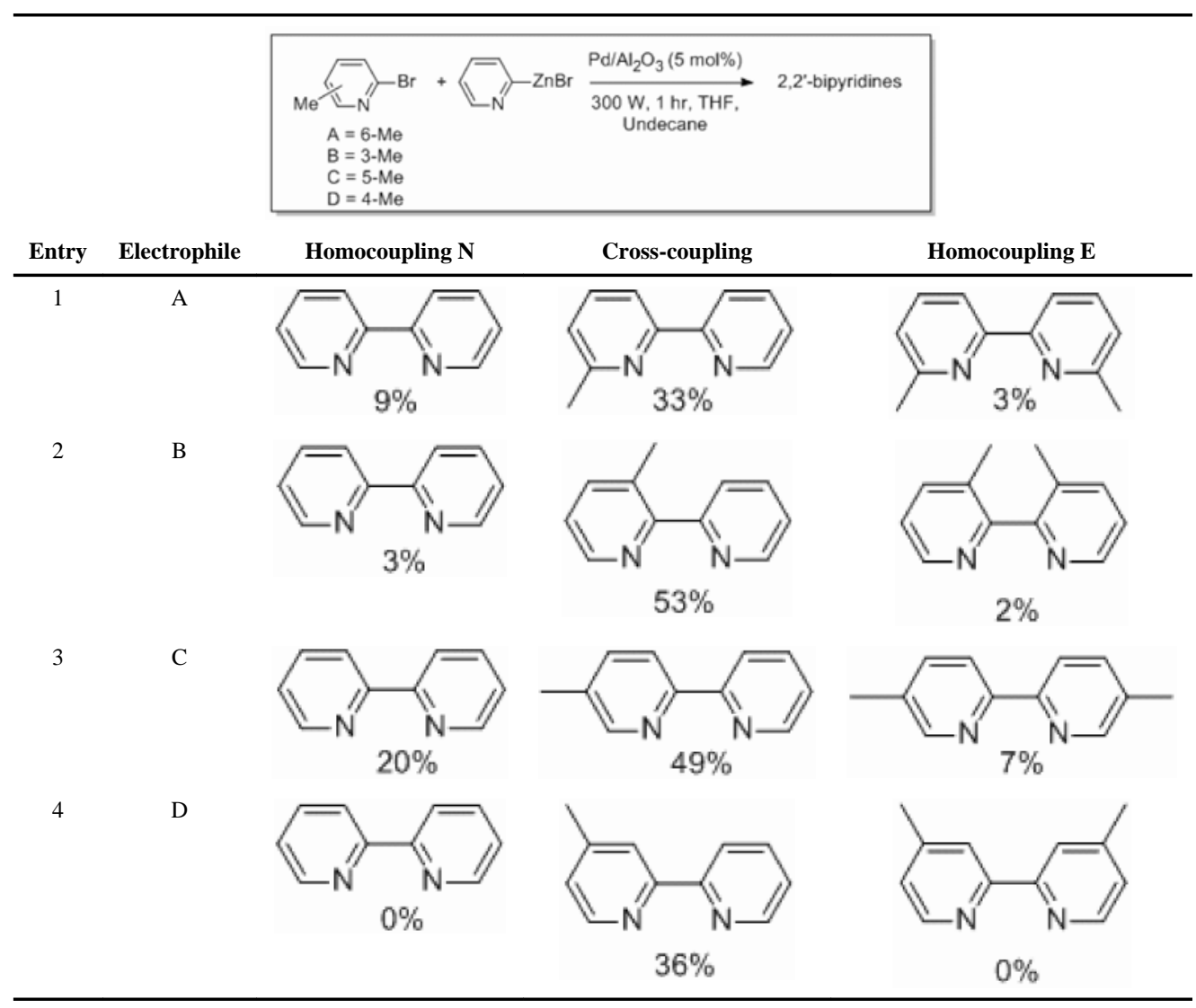

Scale of 2-halopyridines was $0.67 \mathrm{mmol}$. 